\title{
СРАВНИТЕЛЬНЫЙ АНАЛИЗ АНТРОПОМЕТРИЧЕСКИХ, МЕТАБОЛИЧЕСКИХ И ИММУНОЛОГИЧЕСКИХ ПОКАЗАТЕЛЕЙ У ДЕТЕЙ С ИЗОЛИРОВАННЫМ САХАРНЫМ ДИАБЕТОМ 1 ТИПА И ПОЛИГЛАНДУЛЯРНЫМ АУТОИММУННЫМ ПОРАЖЕНИЕМ
}

\author{
'Волкова Н.В., ${ }^{2}$ Солнцева А.В. \\ 'У3 «2 городская детская клиническая больница», Минск, Беларусь \\ гуО «Белорусский государственный медицинский університет», Минск, Беларусь
}

ЦЕЛЬ: на основании выделения и изучения факторов-кандидатов формирования сочетанной аутоиммунной патологии у детей СД 1 типа разработать и внедрить метод комплексного прогнозирования рисков ее развития для оптимизации диагностики, мониторинга и терапии.

Проведено клинико-лабораторное обследование детей с сочетанной аутоиммунной патологией (ос-

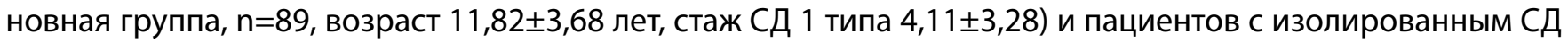

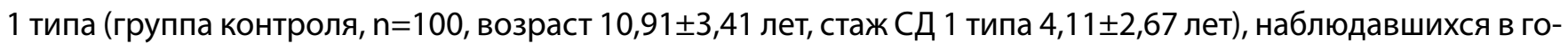
родском детском эндокринологическом центре г. Минска в 2018-2020 гг. Проведена сравнительная оценка физического развития, долговременной компенсации углеводного обмена по уровню гликированного гемоглобина $\left(\mathrm{HbA}_{1 \mathrm{c}}\right)$; тиреоидного статуса (концентрации тиреотропного гормона (ТТГ) и свободного тироксина, уровня антител к тиреоидной пероксидазе (ТПО)), антител к тканевой трансглутаминазе класса $\lg$ А и глиадину IgG, антител к глутаматдекарбоксилазе (GAD), витамина Д. Оценка роста и индекса массы тела (ИМТ) проводилась с использованием z-критерия (ВО3, 2007 г.). Статистическая обработка результатов проведена с использованием программы Excel 2010. Различия считали статистически значимыми при значениях $\mathrm{p}<0,05$.

РЕЗУЛЬТАТЫ: в основной группе у 42 детей отмечено сочетание СД 1 типа с аутоиммунным тиреоидитом (АИТ), у 15 пациентов - с целиакией, у 3 детей - с АИТ и целиакией, у 2 детей - с болезнью Грейвса, у 27 выявлено увеличение уровня антитиреоидных антител. Отмечено, что показатели z-критерия роста и ИМТ в обеих группах соответствовали средним для возраста значениям и достоверно не отличались между собой ( $p=0,47$ и 0,28 соответственно).

Установлено, что уровень $\mathrm{HbA}_{1 с}$ у детей с сочетанной аутоиммунной патологией отвечал субкомпенсации углеводного обмена и был достоверно выше, чем в контрольной группе $(7,99 \pm 1,74 \%$ и 7,49 1,30\%, $\mathrm{p}=0,029)$.

Среди факторов риска аутоиммунного поражения щитовидной железы установлена связь тиреоидной патологии с дефицитом витамина Д ( $\chi^{2}=4,79, p=0,029$, отношение шансов (ОШ) 3,23, 95\% доверительный интервал (ДИ) 1,10-10,46). Выявлена тенденция к более высокому риску у пациентов женского пола (ОШ 1,64, ДИ 0,87-3,12), и с высоким уровнем антител к GAD (ОШ 2,00, ДИ 0,89-10,52, p>0,05). При анализе факторов риска целиакии выявлена тенденция к повышенному риску ее развития у пациентов с аутоиммунной патологией щитовидной железы (ОШ 1,463, ДИ 0,606-3,530, p>0,05), и увеличением уровня антител к GAD (ОШ 2,514, ДИ 0,892-7,085, p>0,05). Не установлено связи риска целиакии с возрастом манифестации, стажем сахарного диабета 1 типа и полом.

\section{выводы.}

1. Отмечены более высокие уровни $\mathrm{HbA1c}$, антител к тканевой трансглутаминазе и антител к тиреоидной трансглутаминазе у детей с полигландулярной аутоиммунной патологией.

2. Выявлен более высокий риск аутомммунных заболеваний щитовидной железы у пациентов с дефицитом витамина Д. В качестве потенциальных факторов риска тиреоидной патологии можно рассматривать высокий уровень антител к GAD, наличие глютеновой энтеропатии, женский пол и период позднего пубертата, а целиакии — высокий уровень антител к GAD. 